\title{
POLUIÇÃO SONORA: SÍNTESE DE PRINCÍPIOS FUNDAMENTAIS DA TEORIA ACÚSTICA
}

\section{SUMMARY OF BASIC PRINCIPLES OF ACOUSTIC THEORY}

\section{Adriano Bressane ${ }^{1}$, Gerson Antonio Santarine ${ }^{2}$, Júnior Cintra Maurício ${ }^{3}$}

\author{
${ }^{1}$ Engenharia Ambiental / UNESP, ab_engamb@yahoo.com.br, \\ ${ }^{2}$ Física / UNESP, santarin@rc.unesp.br, \\ ${ }^{3}$ Física / UNESP, junior.fisica.unesp@hotmail.com
}

\begin{abstract}
RESUMO
Inúmeros são os trabalhos reportados na literatura sobre poluição sonora, com as mais diversas ênfases e enfoques. Todavia, tais publicações não evidenciam os fundamentos da teoria acústica, visando uma caracterização mais apropriada do fenômeno sonoro. O presente trabalho tem por finalidade proporcionar uma fonte alternativa de consulta para aqueles que deparam com a fragmentada e demasiada quantidade de informações, por vezes obstáculo para compreensão física dos principais aspetos da poluição sonora. Aqui são discutidos e apresentados os principais conceitos relacionados às propriedades do som, princípios de propagação e fenômenos sonoros correlatos.

Palavras-chave: Acústica. Fundamentos teóricos. Poluição Sonora.
\end{abstract}

\section{ABSTRACT}

Several studies are reported on noise pollution literature, with many different approaches. However, there are evident in such publications fundamentals of acoustic theory, aiming at a more appropriate characterization of sound phenomenon. This paper aims to provide an alternative source of consultation for those faced with the fragmented and too much information, sometimes an obstacle to understanding main physical aspects of noise pollution. This paper to present and discuss concepts concerning the sound properties, principles of sound propagation and related phenomena.

Keywords: Acoustics. Theoretical fundamentals. Sound pollution. 


\section{INTRODUÇÃO}

Os organismos vivos estão continuamente circundados de energia sob suas mais diversas formas, fundamental para que possa interagir com o meio e, dessa forma, sobreviver (DAY, 1979). Dentre elas, a energia acústica atua como estímulo sobre o indivíduo e quando os níveis sonoros excedem a determinados limites, sua intensidade pode ocasionar respostas psicológicas e químicas como, por exemplo, secreção anormal de hormônios dentre outras alterações físico-somáticas (MEDEIROS, 1999).

A acústica como parte do conhecimento científico é conhecida desde os gregos antigos, mas durante longos anos permaneceu esquecida pela física, permanecendo ligada a idéias filosóficas, não muito afastadas da mística, superstição e magia. Ao longo dos anos foram surgindo os primeiros conceitos vinculados ao movimento oscilatório e a propagação sonora (NEPOMUCENO, 1968).

Somente com a demanda tecnológica no setor de comunicações, nos fins do século XIX, é que os estudos acústicos se aprofundaram, interligando-se a outros campos do conhecimento. Com semelhante expressividade, estudos direcionados à psicoacústica, correlacionando-se os efeitos dos ruídos sonoros sobre o homem revelaram-se como questão de saúde pública (um dos principais problemas da sociedade moderna) desde o Congresso Mundial sobre Poluição Sonora na Suécia, em 1989 (FERNANDES, 2002). Consequentemente, a aplicação da teoria acústica ao estudo e compressão física do fenômeno sonoro tem avançado de maneira significativa.

Atualmente, pesquisas sobre poluição sonora alcançaram diversas áreas de estudo com os mais distintos enfoques. Com o expressivo acúmulo de conhecimentos disponíveis na literatura, uma síntese atualizada dos princípios fundamentais da teoria acústica aqui relatados podem representar contribuição oportuna para pesquisadores e profissionais de outras áreas que se interessem pelo tema, visto que demasiadas informações dispersas podem representar algum obstáculo à compreensão da natureza física da poluição sonora.

\section{MATERIAIS E MÉTODOS}

Trata-se de um trabalho de revisão bibliográfica cujos materiais utilizados compreendem as obras reportadas na literatura especializada e divulgação científica. Os resultados finais subsidiam embasamento cognitivo à elaboração do trabalho em duas partes sendo a primeira, referente ao conjunto de propriedades, conceitos e definições, e a segunda, a princípios de propagação sonora e fenômenos associados. 


\section{RESULTADOS E DISCUSSÃO}

\section{Aspectos gerais}

A poluição sonora constitui-se de um resíduo energético, inodoro e incolor, que não provoca transformações da matéria ou quaisquer outras alterações permanentes ao meio ambiente, representando uma forma incomum de poluição cujas características e propriedades requerem análises mais criteriosas para uma adequada compreensão do fenômeno.

A compreensão de quando o som passa a ser considerado como poluição sonora, ou mesmo supera questões básicas como a diferença entre som e ruído, equivocadamente considerada por muitos como meramente subjetiva, torna-se de expressiva relevância na discussão do significado físico dos princípios fundamentais da teoria acústica.

Conforme a legislação brasileira, o termo poluição representa uma condição de degradação da qualidade ambiental resultante de atividades que, entre outros fatores, prejudiquem a saúde e o bem-estar da população, assim como lancem energia em desacordo com os padrões ambientais, art. $3^{\circ}$ da Lei Federal $n^{\circ}$. 6.938, 1981 (BRASIL, 1981).

Neste sentido, quanto aos níveis sonoros prejudiciais à saúde, órgãos como a Organização Mundial da Saúde (OMS) publicaram padrões de recomendação para exposição humana ao ruído, nos quais as legislações de diversos países se utilizaram para definir seus níveis de admissibilidade.

No Brasil, os níveis sonoros admissíveis para o ruído ocupacional são correlacionados com o tempo de exposição do trabalhador e definidos por normas regulamentadoras expedidas pelo Ministério do Trabalho. No meio urbano, os níveis sonoros admissíveis, tanto para áreas externas quanto para recintos fechados, são definidos conforme o uso e ocupação predominantes em cada área do município, expedidas por normas da Associação Brasileira de Normas Técnicas - ABNT, por sua vez definidas pelo Conselho Nacional do Meio Ambiente - CONAMA.

Fontes específicas, também são regulamentadas por resoluções do Conselho Nacional de Trânsito - CONTRAN, por normas do Instituto Nacional de Metrologia, Normalização e Qualidade Industrial - INMETRO, entre outros.

No contexto deste trabalho é interessante ressaltar que o nível sonoro, comumente avaliado pelos instrumentos de medição, através do nível de pressão sonora, é uma das propriedades acústicas que, por sua vez, relaciona-se com a intensidade e frequência, popularmente denominadas de volume e altura sonora, além de outros fundamentos, cuja compreensão é de fundamental importância para aqueles que pretendem realizar estudos sobre poluição sonora.

Propriedades sonoras, conceitos e definições

Fisicamente, o som corresponde à fração audível de qualquer fenômeno vibratório, resultando de variações da pressão acústica, mediante uma série de 
compressões e rarefações que se propagam em meio suficientemente elástico para tal (GERGES, 2000).

Convem ressaltar que a pressão acústica equivale ao valor instantâneo do desvio de pressão devido à perturbação sonora causada por uma fonte geradora. Assim quando a fonte sonora considerada produz desvios de pressão superiores aos legalmente estabelecidos (Tabela 1) fica caracterizado o fenômeno da poluição sonora.

Tabela 1 - Níveis máximos de pressão sonora admitidos para ambientes externos.

\begin{tabular}{l|c|c}
\hline \multicolumn{1}{c}{ Tipos de áreas } & \multicolumn{2}{c}{ Período } \\
\cline { 2 - 3 } & Diurno & \multicolumn{1}{c}{ Noturno } \\
\hline Áreas de sítios e fazendas & $40 \mathrm{~dB}$ & $35 \mathrm{~dB}$ \\
\hline Área estritamente residencial ou de hospitais ou de escolas & $50 \mathrm{~dB}$ & $45 \mathrm{~dB}$ \\
\hline Área mista, predominantemente residencial & $55 \mathrm{~dB}$ & $50 \mathrm{~dB}$ \\
\hline Área mista com vocação comercial e administrativa & $60 \mathrm{~dB}$ & $55 \mathrm{~dB}$ \\
\hline Área mista, com vocação recreacional & $65 \mathrm{~dB}$ & $55 \mathrm{~dB}$ \\
\hline Área predominantemente industrial & $70 \mathrm{~dB}$ & $60 \mathrm{~dB}$ \\
\hline
\end{tabular}

Fonte: ABNT NBR 10151 (ABNT, 2000).

Por ser um fenômeno periódico, as flutuações de pressão sonora se propagam no meio em forma de ondas sonoras, ditas longitudinais, vez que, a direção de oscilação das partículas coincide com a direção de propagação acústica (WERNER e CASTRO, 2007).

A propagação sonora, portanto, consiste na transmissão da energia acústica a partir do movimento vibratório das partículas componentes do meio que, após serem inicialmente perturbadas, passam a atuar como fontes elementares (Princípio de Huyghens-Fresnel), perturbando novas partículas por colisões quase elásticas e assim consecutivamente, até que a energia acústica seja plenamente consumida, pelas perdas dissipativas que ocorrem durante o processo (FUSINATO, 2005).

Por esta razão, fontes de poluição sonora, como estabelecimentos industriais e casas noturnas, entre outros, precisam ter sua localização suficientemente distanciada de hospitais, escolas e áreas residenciais e/ou possuir tratamento acústico capaz de dissipar a energia acústica excessiva.

O som apresenta comportamento dissipativo com predomínio da ação de forças que tendem a amortecer o movimento vibratório das partículas embora também possam ocorrer eventos em que a fonte sonora mantenha-se continuamente restaurando a energia dissipada, de modo análogo a um oscilador amortecido forçado (FERNANDES, 2002; GERGES, 2000; NEPOMUCENO, 1968).

Neste contexto, a frequência sonora refere-se ao número (por segundo) de ciclos de oscilação da partícula, ou de variações da pressão acústica, que equivale à frequência da fonte, ou conjunto de fontes que geralmente atuam sobre o mesmo campo acústico, sendo, nesse último caso, o resultado de interações que geram um som composto por várias frequências (FONSECA et al., 2002). 
A superposição de frequências suficientemente próximas ou múltiplas podem gerar sons compostos, cuja frequência resulta da combinação das originais, porém, são raros os casos, ocorrendo comumente apenas de modo controlado (em estúdios e equipamentos musicais, por exemplo), em que deseja-se gerar sons agradáveis, denominados consonantes (NEPOMUCENO, 1968).

Em estruturas sólidas, conforme suas propriedades mecânicas, cada sistema possui uma frequência na qual encontra menor resistência a vibração, denominada frequência fundamental. Embora a frequência fundamental sempre seja predominante durante a oscilação tendem a ocorrer frequências derivadas (múltiplos) da fundamental, denominadas harmônicas ou sobretons, cuja sobreposição geram os sons consonantes, conhecidos como timbre sonoro (CARVALHO, 1967).

Outro importante fenômeno vinculado a tais conceitos é a ressonância, na qual corpos com frequências fundamentais semelhantes apresentam máxima eficiência na transmissão de energia, ocasionando as maiores amplitudes de vibração, podendo até mesmo romper estruturas (CROWFORD-JR, 1971).

No ambiente urbano, ou mesmo em recintos fechados, devido à diversidade das fontes atuantes, como resultado geralmente obtêm-se um som complexo (Figura 1) ou, simplesmente, denominado ruído, que possui um espectro de frequências distribuídas ocasionalmente, sem padrão aparente e, geralmente dissonantes, ou seja, auditivamente desagradáveis (BRUIT, 1982 apud MACHADO, 2005).

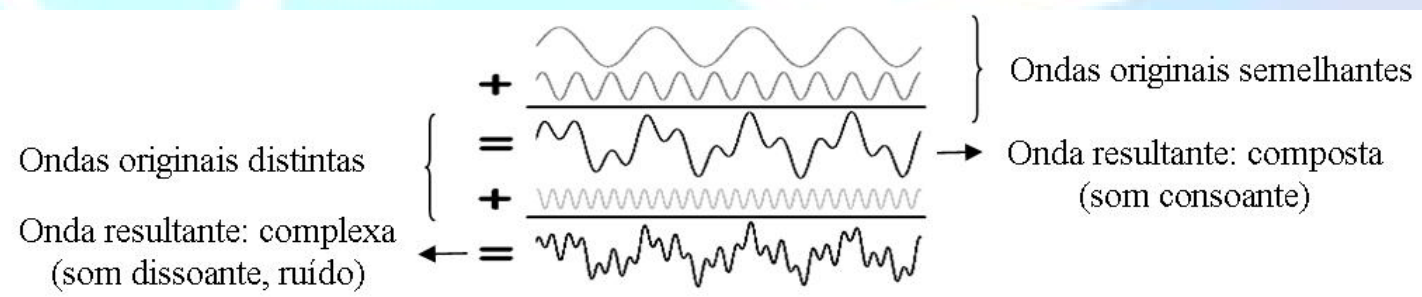

Figura 1. Ruído, som complexo proveniente da interação de fontes diversificadas. Fonte: Modificada a partir de Fonseca et al. (2002).

Devido ao efeito desagradável provocado pela complexa composição do ruído, mesmo em intensidades inferiores ao limites normativos, não raro, são considerados como poluição sonora. Devido ao caráter subjetivo desta percepção, não existe previsão normativa que permita uma avaliação e controle para tais circunstancias.

Conforme Nepomuceno (1968), no espectro sonoro audível humano, aproximadamente entre 20 e $20 \mathrm{kHz}$, as frequências, que em termos da percepção auditiva também são denominadas altura sonora, podem variar de graves equivalentes a faixa de 20 a $500 \mathrm{~Hz}$, médio ou de 500 a $4 \mathrm{kHz}$, e acima deste valor até $20 \mathrm{kHz}$, classificados como agudos.

$\mathrm{Na}$ faixa audível verifica-se que o ouvido humano percebe as frequências de maneira não-linear obedecendo a uma escala logarítmica, conforme a Leis de Weber para relação estímulo/sensação (SEKULER e BLAKE, 1994). 
Consequentemente, quando a relação entre suas frequências coincide, os sons são percebidos iguais ao ouvido humano. Convencionou-se denominar de uma oitava a razão igual duas entre frequências sonoras consecutivas, tal como exemplificado pelas expressões abaixo:

$$
\frac{200}{100}=\frac{400}{200}=\frac{800}{400}=2 \rightarrow 1 \text { oitava }
$$

A intensidade sonora corresponde ao fluxo médio de energia acústica por unidade de superfície, em direção normal a propagação e, popularmente, também é conhecida como volume sonoro (NEPOMUCENO, 1968). Conforme a equação abaixo, a intensidade sonora $(I)$ é proporcional aos quadrados da frequência $(f)$ e amplitude $(A)$ :

$$
I=k \cdot f^{2} \cdot A^{2}\left[W / m^{2}\right]
$$

Assim, durante o movimento oscilatório, o deslocamento máximo da partícula em relação ao ponto médio da trajetória de oscilação (posição de equilíbrio), denominado amplitude, é diretamente proporcional a energia acústica propagada (FERNANDES, 2002). Assim, durante a dissipação sonora a amplitude de movimento vai sendo amortecida, porém, a frequência de oscilação se mantém constante (Figura 2).

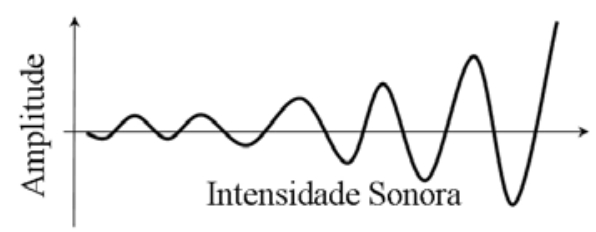

Figura 2. Correlação da amplitude de oscilação com a intensidade sonora.

Esta progressiva redução na amplitude de oscilação é responsável pela diminuição do nível de intensidade sonora e, conseqüentemente, pela dissipação da poluição sonora ao longo da distância percorrida. Neste cenário, o comprimento de onda corresponde à distância percorrida pelo som durante um ciclo completo de oscilação da partícula, sendo o tempo gasto nesse percurso, denominado período (Figura 3).

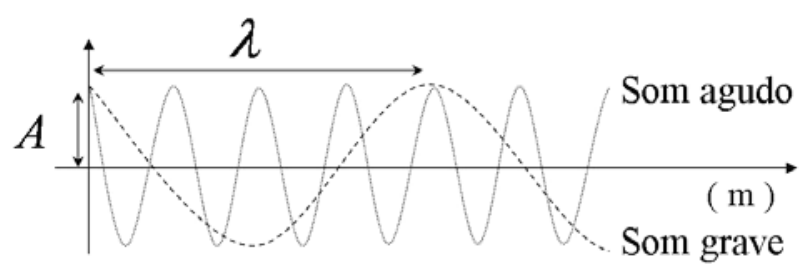

Figura 3. Esquema representativo da amplitude $(A)$ e comprimento de onda $(\lambda)$. 
Outro importante conceito é o de ângulo de fase que equivale à fração completada do ciclo pela onda, durante um determinado tempo não coincidente com o período (LAZZARINI, 1998).

Visando compatibilizar-se com a percepção do ouvido humano que tem comportamento não linear o qual apresenta enorme sensibilidade capaz de perceber extensa gama de variações adotou-se uma escala com graduação logarítmica, denominada decibel (dB), a partir da qual o nível sonoro (ou nível de ruído) pode ser mais eficientemente calculado (FERNANDES, 2002).

Vale salientar que o decibel equivale a uma relação entre valor usualmente obtidos com medições em campo e valores adotados como referência padrão resultando em uma grandeza adimensional não sendo, portanto, considerado como unidade acústica, mas apenas uma escala logarítmica de referência.

Em acústica tais valores podem corresponder à intensidade sonora (energia acústica por unidade de área $-I\left[\mathrm{Watt} / \mathrm{m}^{2}\right]$ ), a pressão acústica (diferencial de pressão $-P-\left[\mathrm{N} / \mathrm{m}^{2}\right]$ ), ou mesmo a potência acústica (energia acústica por unidade de tempo $W$ - [Watt]), resultando, respectivamente, no nível de intensidade sonora (NIS), nível de pressão sonora (NPS) e nível de potência sonora $(N W S)$, conforme as expressões:

$$
N S=N P S=20 \log \frac{P}{P_{r e f}} ; \quad N S=N W S=10 \log \frac{W}{W_{\text {ref }}} ; \quad N S=N I S=10 \log \frac{I}{I_{\text {ref }}}
$$

nas quais o numerador corresponde ao valor mensurado e o denominador ao valor de referência determinado como limiar da audibilidade humana.

Os níveis sonoros $(N S)$ são graduados em decibéis e, a partir resposta auditiva humana, obtém-se uma faixa que varia de 0 a $120 \mathrm{~dB}(\mathrm{~A})$, correspondendo respectivamente ao limiar da audição e ao máximo audível (dor) . Como o ruído apresenta frequências significativamente variáveis, a simbologia $\mathrm{dB}(\mathrm{A})$ denota que os níveis sonoros avaliados são ponderados conforme a sensibilidade do ouvido humano, sendo mais eficiente na banda espectral que varia de $1 \mathrm{a} 4 \mathrm{kHz}$.

Conforme seu comportamento ao longo do tempo, o ruído ainda pode ser classificado como contínuo ou descontínuo, quando as variações do nível sonoro são, respectivamente, inferiores ou superiores a $6 \mathrm{~dB}(\mathrm{~A})$, durante um intervalo de 5 minutos. Quando se observam picos de energia acústica com duração inferior a um segundo, o ruído é classificado como impulsivo ou ruído de impacto (CETESB, 1992).

\section{Propagação sonora e fenômenos associados}

Segundo Gerges (2000), durante a propagação do som, devido ao movimento oscilatório das partículas a transmissão da energia acústica gera zonas de alta e baixa densidade, frentes de compressão e rarefação, ou simplesmente, frentes de onda que se propagam tridimensionalmente a partir da fonte sonora (Figura 4). 


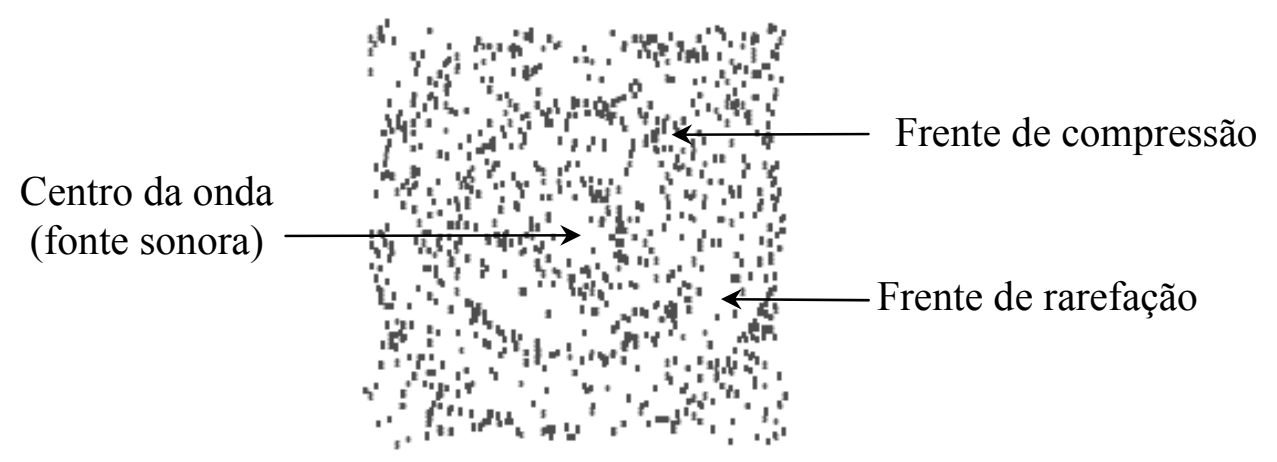

Figura 4. Esquema didático para representação de frentes de compressão e rarefação de ondas para uma fonte acústica puntual.

$\mathrm{Na}$ ausência de obstáculos a partir da fonte geradora a propagação sonora ocorre sem obstrução em todas as direções, na forma de uma onda tridimensional esférica, semi-esférica ou cilíndrica, dependendo das características da fonte, e mesmo podendo ser considerada plana quando suficientemente distante desta fonte ou em campos acústicos confinados (NEPOMUCENO, 1968).

A velocidade de uma onda sonora depende das propriedades elásticas e inerciais do meio que desempenham um papel importante na transmissão de energia sonora, pois corpos plásticos retêm parte da energia que provocou sua deformação, sendo, portanto, tanto mais eficiente quanto mais elástico for o meio, embora, para pequenas deformações todos os corpos possam ser considerados elásticos.

Experimentos práticos demonstram que o som se propaga mais rápido em temperaturas maiores, assim como nos sólidos em relação aos líquidos e nestes últimos, mais rápido que nos gases (FERNANDES, 2002; NEPOMUCENO, 1968).

A inércia e a elasticidade do meio estão relacionadas a variações de umidade, mas principalmente a sua densidade $(D)$, pressão $(P)$ e a temperatura $(T)$, conforme expressa a equação, abaixo que evidencia uma aproximação para a velocidade $(v)$ de propagação no intervalo de -30 e $30^{\circ} \mathrm{Celsius} \mathrm{(FERNANDES,} \mathrm{2002).}$

$$
v=\sqrt{1,4 \frac{P}{D}}+0,607 T
$$

Mesmo na ausência de obstáculos o som sofre atenuações ao se propagar livremente em conseqüência de um conjunto de condicionantes ambientais como absorção atmosférica, variação de temperatura, efeito do vento e dispersão das ondas com a distância percorrida (GERGES, 2000).

Com o distanciamento das frentes de onda em relação à fonte, ocorre um contínuo aumento das áreas $(A)$ compostas por essas frentes de onda e, como conseqüência uma diluição por unidade de área da energia acústica propagada tornando a intensidade sonora cada vez menor até não ser mais percebida (FERNANDES, 2002).

Segundo para uma fonte sonora puntiforme a intensidade $(I)$ sonora diminui 
com o quadrado da distância $(d)$ em relação à fonte, assim como a amplitude $(A)$ de oscilação das partículas, Nepomuceno (1968), conforme as equações a seguir:

$$
I_{1} / I_{2}=d_{1}^{2} / d_{2}^{2} \text { e } A_{1} / A_{2}=d_{1} / d_{2}
$$

Como o ar não se comporta como meio perfeitamente elástico, durante as sucessivas compressões e rarefações vários processos irreversíveis relacionados à viscosidade e condução de calor ocorrem tendo como conseqüência a uma atenuação da energia sonora, conhecida como absorção clássica (GERGES 2000).

Conforme Fernandes (2002), as trocas térmicas provocadas por sucessivas compressões e expansões no meio, geram calor e, como conseqüência as perdas entrópicas, diretamente proporcionais à frequência, e inversamente proporcionais à temperatura e à umidade, não estão sujeitos á influência da pressão atmosférica.

Este processo de contração e rarefação deve ser considerado adiabático, argumentando que em condições normais, enquanto uma onda sonora de $1 \mathrm{kHz}$ percorre seu ciclo completo, uma onda de difusão térmica de mesma frequência, percorre uma distância 70 vezes menor, portanto, considerada desprezível. Entretanto, segundo Nepomuceno (1968).

Assim, o som comporta-se com um fenômeno dissipativo, no qual predomina a ação de forças cuja resultante tende a amortecer o movimento das partículas. Fenômenos dessa natureza podem ser analisados através equação de balanço energético conhecida como equação de Lagrange.

$$
M_{m} \ddot{\xi}+R_{m} \dot{\xi}+s \xi=F(t)
$$

Tal equação representa o comportamento de um oscilador harmônico amortecido-forçado, cujos termos que compõem a força resultante $(F)$ representam, respectivamente, as forças de inércia, de atrito e elásticas atuantes no meio de propagação, onde $\xi$ representa a variável de deslocamento da partícula (a amplitude de oscilação), $M$ a sua massa, $R$ uma constante de atrito e $s$, a rigidez (resistência a deformação) do meio (NEPOMUCENO, 1968). A não uniformidade do meio causada por ventos e/ou gradientes de temperatura, assim como a presença de obstáculos e características estruturais da fonte tendem a induzir trajetórias preferenciais de propagação sonora, conhecida como diretividade. Esta característica representa um fator importante para a análise da propagação sonora, sendo encontrada na literatura algumas correlações com tipo de fonte. Nesse sentido, segundo Gerges (2000), a atenuação com a distância depende da distribuição das fontes de ruído, sendo os principais modelos representados pelas fontes: pontual simples, linear, pontual em linha e fonte plana.

Outro aspecto importante é que são comuns interações entre ondas sonoras 
movendo-se independentemente que, ao cruzarem-se na mesma região do espaço, provocam interferências no deslocamento das partículas, conhecido como princípio de superposição (PALANDI, 2001). Consequentemente, qualquer movimento ondulatório pode ser decomposto em uma combinação de movimentos mais simples.

Assim sendo se duas ondas se encontram em fase (seus máximos de amplitude se encontram coincidentemente na mesma posição) haverá uma interferência construtiva, onde a onda resultante terá s soma das amplitudes das ondas originais. Se por outro lado as ondas estiverem fora de fase os máximos se superporão aos mínimos, ocorrendo uma interferência destrutiva (FONSECA et al., 2002).

$\mathrm{O}$ fenômeno da interferência é conseqüência direta da superposição de ondas, mas o resultado final não depende apenas das fases, amplitudes e frequências das ondas superpostas, mas, sobretudo, de uma aritmética vetorial envolvendo as direções de propagação de cada oscilação. Na realidade quotidiana são mais comuns os casos intermediários a interação construtiva e destrutiva, onde há uma interferência parcial, gerando uma nova onda com amplitude intermediária (Figura 5).

a

$\mathrm{b}$
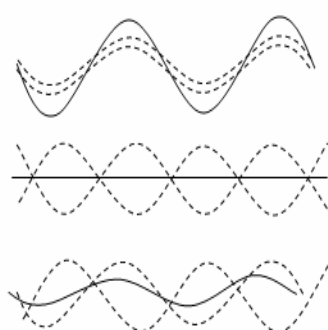

Ondas originais

-Onda resultante

Figura 5. Interações ondulatórias construtiva (a), destrutiva (b) e intermediária (c).

De forma semelhante aos casos intermediários, quando durante a superposição de ondas as frequências ocorrem, alternadamente, concordância e oposição de fase em intervalos de tempos constantes, estes são denominados período de batimento.

Segundo Nepomuceno (1968), o batimento pode ser interpretado como uma frequência de acoplamento entre ondas, constituindo-se dessa forma, uma frequência de ressonância resultante para o acoplamento dessas duas ou mais ondas. $\mathrm{O}$ batimento só ocorrerá, nesses termos, se as frequências originais de cada onda forem aproximadamente iguais e, ainda, se as condições ambientais, como rigidez do meio, por exemplo, permitirem uma eficiente troca de energia entre elas. Caso contrário, o que se observa é a formação de um som composto por inúmeras frequências aleatórias (ruído).

$\mathrm{Na}$ presença de obstáculos, o comportamento do som ao interagir com superfícies e o interior de materiais durante o percurso de propagação sonora compõem a principal perspectiva de estudo, sendo a transmissão, a absorção, a refração, a reflexão e a difração, os principais fenômenos de interesse. Conforme as propriedades físicas tanto da onda incidente quanto do material poderá haver diferentes proporções desses fenômenos, expressados pelos seguintes coeficientes: 


$$
c_{\text {abs }}=\frac{\text { energia absorvida }}{\text { energia incidente }} ; c_{\text {ref }}=\frac{\text { energia refletida }}{\text { energia incidente }} ; \text { e } c_{\text {trans }}=\frac{\text { energia transmitida }}{\text { energia incidente }}
$$

O coeficiente de absorção $\left(c_{a b s}\right)$ corresponde à fração de energia acústica dissipada que foi incorporada pelo material (plástico) e/ou transformada na forma de calor. O de reflexão corresponde à fração da energia sonora que retorna ao meio de origem após a interação com o material e, por último, o coeficiente de transmissão equivale à fração que atravessa o material (FERNANDES, 2002).

$\mathrm{Na}$ reflexão sonora, quando as ondas encontram uma superfície material, os pontos do obstáculo, ao vibrarem, tornam-se uma nova fonte para onda refletida. Por ser resultado da vibração do obstáculo, a geração das ondas refletidas podem ser de alguma forma favorecidas pelas características físicas e geométricas do material. A este respeito, a reflexão superficial é diretamente proporcional à dureza do material. Paredes de concreto, mármore e revestidas por azulejos e vidro, por exemplo, refletem quase a totalidade do som incidente (ABEL, 2006).

Da mesma forma, a reflexão de comprimentos de onda maiores ocorre melhor em superfícies proporcionalmente grandes, o que também poderia ser manipulado alterando-se a geometria desta superfície, em formato de cunhas, aumentando-se a superfície total, mas dividindo-a em áreas relativamente menores.

O conhecimento destas propriedades é fundamental para o controle da poluição através de materiais capazes de proporcionar o amortecimento acústico (conversão de energia acústica em térmica) ou o seu isolamento por reflexão (impermeabilização acústica de uma superfície).

De modo geral, a reflexão sonora obedece às leis básicas da reflexão ondulatória em meios materiais elásticos, podendo ocasionar fenômenos associados como reforço, reverberação e eco (FERNANDES, 2002). O ouvido humano é capaz de diferenciar dois estímulos breves e sucessivos, apenas se o intervalo de tempo entre eles for maior ou igual a $1 / 10$ de segundo.

Quando o som breve direto atinge o tímpano, o estimulo completo dura justamente um décimo de segundo. Se o som refletido chegar em tempo muito menor a esse, ele apenas reforça a excitação do tímpano e a intensidade do som direto.

$\mathrm{Na}$ reverberação, um caso particular de reforço, o som breve refletido chega ao ouvido antes que o tímpano, já excitado pelo som direto, tenha tempo de se recuperar (fase conhecida como persistência auditiva), prolongando a sensação auditiva, mesmo depois que a fonte foi cessada. O tempo de reverberação corresponde ao intervalo necessário para que o nível de intensidade sonora caia $60 \mathrm{~dB}$ a partir do instante em que a fonte sonora for cessada (NEPOMUCENO, 1968).

$\mathrm{O}$ eco ocorre quando o som refletido chega ao tímpano após ele ter-se recuperado do estimulo provocado pelo som direto, ou seja, num tempo igual ou superior a 1/10 de segundo, permitindo a ele discernir as duas excitações.

Ainda por conseqüência das reflexões, pode ocorrer a formação de ondas sonoras estacionárias, quando a onda refletida retorna sobre si mesma, mas em 
sentido oposto. Isso provoca, por superposição das ondas direta e refletida a ocorrência de nós (pontos fixos por interferência destrutiva) e antinós (pontos de máxima amplitude por interferência construtiva). Este fenômeno ocorre mais comumente em campos ondulatórios limitados, como em colunas gasosas aprisionadas em tubos, por exemplo.

A refração sonora corresponde ao desvio sofrido pela trajetória da onda quando ela passa de um meio $(A)$ para outro $(B)$, com características físicas diferentes, provocando uma variação na sua velocidade $(v)$ de propagação, pela maior ou menor resistência oferecida pelo meio, mais especificamente de sua maior ou menor impedância acústica, mas sua frequência $(f)$, que depende apenas da fonte emissora, se mantém inalterada, sendo alterado apenas o comprimento de onda $(\lambda)$, conforme a expressão abaixo (CROWFORD-JR, 1971):

$$
v=f . \lambda \text { e } f_{A}=f_{B} \rightarrow \frac{v_{A}}{\lambda_{A}}=\frac{v_{B}}{\lambda_{B}}
$$

A impedância acústica é composta por duas grandezas, a resistência e a reatância (NEPOMUCENO, 1968). A resistência acústica (medida em ohms acústicos) é função da densidade do meio e, consequentemente, afeta a velocidade de propagação sonora, mas não depende da frequência resultante da onda. Já a reatância acústica é justamente a parte da impedância que está relacionada com a frequência e é proveniente do efeito produzido pela massa (sua inércia) e a elasticidade do meio material.

Tomando-se o ar e água como exemplos, para o som, o ar é mais refringente (coeficiente de refração - $\eta$ maior) porque sua impedância é maior (a onda sonora se desloca com maior velocidade na água do que no ar). Tal como a reflexão, a refração sonora também obedece às mesmas leis comuns a refração ondulatória, a respeito de raios incidentes e refratados serem coplanares, e os respectivos ângulos $(\phi)$ respeitarem a equação de Snell - Descartes:

$$
\eta_{1} . \operatorname{sen} \varphi_{1}=\eta_{2 . \operatorname{sen} \varphi_{2}}
$$

Pela lei de Snell, pode-se mostrar que o som passa de um meio com menor impedância para outro, de maior impedância, em qualquer que seja o ângulo de incidência, mas no sentido contrário, para ângulos maiores a certo ângulo crítico, a onda sonora é totalmente refletida.

Pelo princípio de Huyghens-Fresnel, quando uma partícula passa a vibrar estimula novas partículas que também passam a vibrar, comportando-se como novas fontes de ondas, ditas elementares. Com isso, a sobreposição resultante dessas ondas elementares formam a frente de onda (Figura 6). 


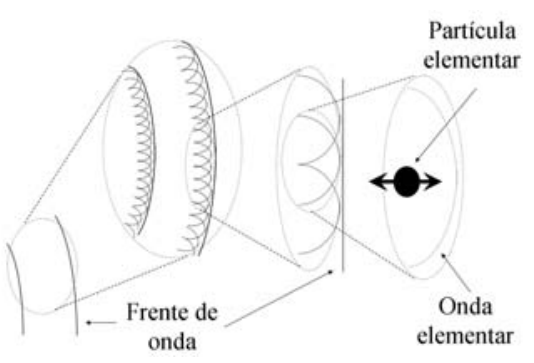

Figura 6. Representação esquemática do Princípio de Huyghens-Fresnel.

Esse princípio explica a capacidade de uma onda sonora reconstituir-se após um obstáculo, contornando-o ou passando por uma abertura, conhecida como difração (MÁXIMO e ALVARENGA, 2000). Essa reconstituição ocorre através das ondas elementares, recompondo a frente de onda.

Como o comprimento das ondas sonoras é muito grande, a difração sonora é bastante significativa, principalmente para os sons graves (baixa frequência) que, portanto, encontram maior facilidade de se propagarem (FERNANDES, 2002). Por sua vez, ondas sonoras com pequeno comprimento de onda (alta frequência) geram regiões de sombra acústica $(S)$ ao contornar obstáculos (Figura 7).

a)

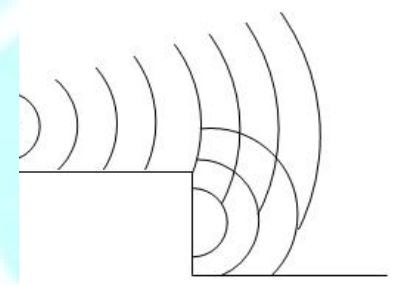

b)

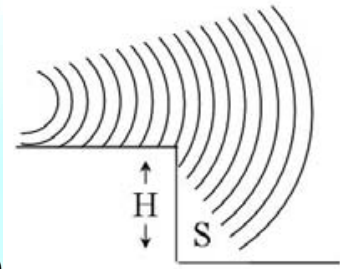

c)

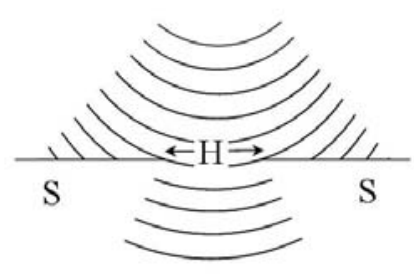

Figura 7. a) Ondas de alta (a) e baixa (b e c) frequência contornando um obstáculo. Fonte: Modificado a partir de Fernandes (2002)

Em síntese, a difração do som em um obstáculo depende do valor relativo entre o tamanho $(H)$ do obstáculo e o comprimento de onda sonora, ocorrendo sombra quando o comprimento de onda é muito menor que o tamanho do obstáculo ou furo. Devido a este fenômeno o controle da poluição sonora na fonte e no meio de propagação através do tratamento acústico de ambientes deve ser cuidadosamente planejado para que seja capaz de efetivamente proporcionar o efeito desejado.

\section{CONSIDERAÇÕES FINAIS}

A poluição sonora como agente da emissão de energia acústica em níveis superiores aos padrões legais admissíveis, representa uma forma de degradação da qualidade ambiental em muitos aspectos, mas, diferentemente de outros tipos de poluentes tais como, químicos, nucleares ou de outra natureza devido à sua característica eminentemente física não deixa quaisquer traços de resíduos. 
Neste sentido seus impactos ao meio ambiente são invisíveis, mascarando-se as heranças prejudiciais da vida moderna. A necessária caracterização física da poluição sonora contribui significativamente para sua percepção e tratamento, cuja adequada compreensão ainda hoje pode estar prejudicada apesar de não seja rara a literatura a respeito pulverizada demasiadamente de informações.

Neste contexto a presente revisão de aspectos da teoria acústica apresentada de forma bastante sintética nos quais muitos conceitos fundamentais, características de propriedades sonoras, princípios de propagação e fenômenos associados, pretende constituir-se de uma fonte alternativa de literatura a qual pode colaborar para superação de obstáculos comuns à iniciantes pouco familiarizados com o tema.

\section{REFERÊNCIAS}

ABEL - ACÚSTICA BRASILEIRA ENGENHARIA LTDA. Informações sobre tratamento acústico. Disponível em http://www.abel-acustica.com.br. Acesso em: 10 nov de 2006.

ABNT - ASSOCIAÇÃO BRASILEIRA DE NORMAS TÉCNICAS. NBR 10.151: Avaliação do ruído em áreas habitadas visando o conforto da comunidade. Rio de Janeiro, 2000.

BRASIL. Política Nacional do Meio Ambiente. Lei no . 6.938 de 1981. Disponível em: $<$ http://www.planalto.gov.br $>$. Acesso em: 06 Jun. 2007.

CARVALHO, B. A. Acústica aplicada à arquitetura. Rio de Janeiro: Freitas Bastos, 1967.

CETESB - COMPANHIA AMBIENTAL DO ESTADO DE SÃO PAULO. Determinação do nível de ruído em ambientes internos e externos de áreas habitadas: método de ensaio. Norma Técnica L11.032. São Paulo, 1992.

CROWFORD-JR, F. S. Waves: berkeley phisics course - vol 3. Barcelona: Reverté, 1971.

DAY, R. H. Psicologia da Percepção. $3^{\text {a }}$ ed. Rio de Janeiro: J. Olympio, 1979.

FERNANDES, J. C. Acústica e Ruídos. Apostila (Acústica e Vibrações). Faculdade de Engenharia, Universidade Estadual Paulista, Bauru, 2002.

FONSECA H.; SANTOS, V.; FERREIRA, A. A natureza física do som. Disponível em http://www.telecon.inescn.pt. Acesso em: 10 de out de 2002. 
FUSINATO, V.A. Mini-curso de acústica e ruídos. Apostila (Acústica e Vibrações). Departamento de Física, Universidade Estadual de Maringá, Paraná, 2005.

GERGES, S. N. Y. Ruído: fundamentos e controle. $2^{\mathrm{a}}$ ed. Florianópolis: NR Editora, 2000.

LAZZARINI, V.E.P. Elementos de acústica. Apostila (Acústica e Vibrações). Music Department, National University of Ireland, Maynooth, 1998.

MACHADO, P.A.L. Direito Ambiental Brasileiro. 13 ${ }^{\text {a }}$ Ed. São Paulo: Malheiros, 2005.

MÁXIMO, A.; ALVARENGA, B. Curso de Física. São Paulo: Scipione, 2000.

MEDEIROS, L.B. Ruído: Efeitos extra-auditivos no corpo humano. 1999. 33 f. Monografia (Especialização em Audiologia Clínica) - Centro de Especialização em Fonoaudiologia Clínica. CEFAC, Porto Alegre, RS. 1999.

NEPOMUCENO, L.X. Acústica Técnica. São Paulo: Ed. Técnico-Gráfica Industrial Ltda, 1968.

PALANDI, J.Oscilações e ondas. Santa Maria: UFSM, 2001.

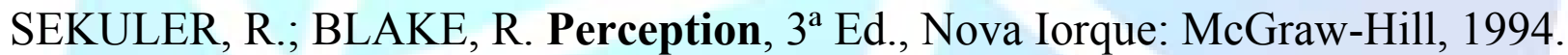

WERNER, J. C.; CASTRO, E. R. Controle acústico ativo de ruídos em dutos. Disponível em http://www.usp.br. Acesso em: 10 de jun de 2007. 